\title{
ADUBAÇÃO FOSFATADA E NUTRIÇÃO FOLIAR NA CULTURA DA SOJA EM SOLO COM FERTILIDADE EM CONSTRUÇÃO
}

\author{
Cassiano Cavalli ${ }^{1}$, Anderson Lange ${ }^{2}$, Edilson Cavalli ${ }^{3}$, Flávio Jesus Wruck ${ }^{4}$, Patrick Hayra \\ dos Santos $^{5}$
}

\footnotetext{
${ }^{1}$ Mestrando em Agricultura Tropical e Subtropical, IAC, Campinas (SP). Email: cavallicassiano@ gmail.com

2 Docente do Instituto de Ciências Agrárias e Ambientais, UFMT, Sinop (MT). Email: paranalange@ hotmail.com

${ }^{3}$ Doutorando em Agricultura Tropical e Subtropical, IAC, Campinas (SP) .Email: edilso_c@ hotmail.com

${ }^{4}$ Pesquisador do Núcleo da Embrapa Arroz e Feijão no Estado do Mato Grosso, Sinop (MT). Email: flavio.wruck@embrapa.br

5 Assistente de Pureza Genética, GDM - Genética do Brasil, Lucas do Rio Verde (MT). Email: patricksantyos@hotmail.com
}

RESUMO: O objetivo do trabalho foi avaliar um programa de adubação na soja em que se variou a dose de fósforo na semeadura, as doses de fertilizantes via jato dirigido no sulco e a aplicação de potássio e enxofre foliar. O experimento foi conduzido na área da Agropel Sementes, localizada no município de Sinop e os tratamentos consistiram-se de um fatorial $(4 \times 5 \times 2)$ resultante de doses $\left(0,30,60\right.$ e $\left.90 \mathrm{~kg} \mathrm{ha}^{-1}\right)$ de $\mathrm{P}_{2} \mathrm{O}_{5}$ aplicadas a lanço na semeadura, doses de fertilizante líquido contendo $11 \%$ de $\mathrm{N}$ e $37 \%$ de $\mathrm{P}_{2} \mathrm{O}_{5}$, aplicado no sulco de semeadura $\left(0,5,10,15\right.$ e $\left.20 \mathrm{~L} \mathrm{ha}^{-1}\right)$ e presença ou ausência de $2 \mathrm{~L} \mathrm{ha}^{-1}$ de fertilizante foliar contendo $37 \%$ de $\mathrm{K}_{2} \mathrm{O}$ e $25 \%$ de $\mathrm{S}$ aplicado em $\mathrm{R} 3$, dispostos em um delineamento em blocos casualizados com quatro repetições. A altura de plantas, a produtividade e o teor de fósforo e potássio no solo apresentaram diferença significativa em relação às doses de fósforo de base. Em relação à adubação foliar, a altura de plantas foi significativa. A aplicação de fósforo de base aumentou a concentração do nutriente no solo repercutindo assim em maior produtividade.

Palavras-chave: Fósforo. Glycine max. Produtividade.

\section{PHOSPHATE FERTILIZATION AND LEAF NUTRITION IN SOYBEAN CROP IN A SOIL UNDER FERTILITY CONSTRUCTION}

\begin{abstract}
The objective of this study was to evaluate a soybean crop in the fertilization program that ranged phosphorus rate at sowing, the rates of fertilizers through jet directed into the furrow and applying potassium and sulfur via leaf. The experiment was conducted in the area of Agropel Sementes, in the Sinop county and the treatments consisted of a factorial ( $4 \times 5 \times 2$ ) resulting from rates $\left(0,30,60\right.$ and $\left.90 \mathrm{~kg} \mathrm{ha}^{-1}\right)$ applied $\mathrm{P}_{2} \mathrm{O}_{5}$ broadcasted at sowing, liquid fertilizer rates containing $11 \% \mathrm{~N}$ and $37 \% \mathrm{P}_{2} \mathrm{O}_{5}$, applied in the planting furrow $\left(0,5,10,15\right.$ and $\left.20 \mathrm{~L} \mathrm{ha}^{-1}\right)$ and the presence or absence of $2 \mathrm{~L} \mathrm{ha}^{-1}$ fertilizer leaf containing $37 \% \mathrm{~K}_{2} \mathrm{O}$ and $25 \% \mathrm{~S}$ applied to $\mathrm{R} 3$ disposed in a randomized block design with four replicates. The plant height, productivity and phosphorus and potassium in the soil showed a significant difference from phosphorus rates. The leaf fertilizer influenced plant
\end{abstract}


height. The phosphorus application increased the concentration of the nutrient in the soil thus resulting in higher productivity.

Key words: Phosphor. Glycine max. Productivity.

\section{INTRODUÇÃO}

A cultura da soja é amplamente difundida no Brasil por proporcionar uma boa rentabilidade para o produtor, sendo cultivada principalmente no Cerrado, local com características de solos ácidos, grande quantidade de alumínio tóxico, baixos teores de nutrientes e alta fixação de fósforo, sendo importante suprir as exigências nutricionais dessa cultura a fim de obter produtividades satisfatórias, porém reduzindo os custos de produção, aumentando dessa forma a lucratividade.

Um dos nutrientes que mais limita a produtividade das culturas no Brasil é o fósforo (P), que segundo Malavolta (2006) está presente em membranas biológicas, armazenamento de energia na fotossíntese e respiração que será utilizada em outros processos, em sua maioria na forma de ATP. Restrições de P no início do desenvolvimento da planta podem causar danos irreversíveis à cultura, mesmo com a adição do nutriente. Os sintomas de deficiência incluem redução na altura da planta, brotação e desenvolvimento de raízes secundárias, atraso na emergência das folhas, na produção de matéria seca e de sementes (GRANT et al., 2001).

Como o P representa uma parcela muito grande dos custos de produção, uma alternativa é disponibiliza-lo de forma mais eficiente. Segundo Bedin et al. (2003), adubação fosfatada no Brasil é imprescindível, para que se consigam boas produtividades nas culturas, levando-se em conta a importância de utilizar uma fonte de $\mathrm{P}$ com liberação que coincide com a necessidade da cultura. É importante que o P esteja próximo da raiz, pois se move até as raízes principalmente por meio de difusão, que é um mecanismo muito lento (GRANT et al., 2001)

Mais recentemente os solos de Cerrado tem apresentado deficiência de enxofre (S), devido ao uso de formulados concentrados, das maiores produtividades, do uso inadequado do solo. O S é constituinte de várias coenzimas e vitaminas e é encontrado em aminoácidos como cistina, cisteína e metionina (TAIZ; ZEIGER, 2013). É absorvido na forma de $\mathrm{SO}_{4}{ }^{2-}$, que normalmente não se acumula na superfície do solo, por ser bastante móvel (CANTARELLA; MONTEZANO, 2010).

O S é suprido principalmente pelo mecanismo de fluxo de massa, quando o nutriente está em concentrações elevadas no solo apenas o fluxo de massa é suficiente para suprir as necessidades da planta, porém quando as concentrações são baixas o fluxo de massa não é suficiente, necessitando que parte da quantidade do nutriente chegue até a raiz por difusão. Outra forma que o enxofre pode ser absorvido é pela folha, podendo a absorção direta nas folhas ocorrer de forma oxidada ou reduzida (SILVA et al., 2002). Rezende et al. (2009) 
utilizando enxofre em adubação foliar observaram aumento na produtividade de grãos da cultura da soja.

O potássio $(\mathrm{K})$ que na forma catiônica $\mathrm{K}+$ tem um papel importante na planta como regulador de potencial osmótico celular e ativador de enzimas presentes em processos como respiração e fotossíntese (TAIZ; ZEIGER, 2013). Tem funções na abertura e fechamento estomático e translocação de açúcares, atuando também na fixação biológica de nitrogênio (MALAVOLTA, 2006). Sendo o cátion presente em maior abundância na planta, não fazendo parte de nenhuma estrutura (MEURER, 2006).

Grãos pequenos, enrugados e deformados, atraso na maturidade da soja, haste verde, retenção foliar e vagens chochas podem ocorrer pela falta de K (BORKERT et al., 1994). Sendo um nutriente importante no controle das doenças fúngicas como a seca da vagem e da haste, crestamento foliar e mancha púrpura da semente e cancro da haste que tem incidência nos estádios fenológicos R3 à R4 da soja (MASCARENHAS et al., 2004). Antracnose e doenças de final de ciclo têm como uma das medidas de controle a adubação equilibrada com ênfase no K (BORKERT et al., 1994).

A carência de $\mathrm{K}$ na planta pode ocorrer pelo fato dos solos do Cerrado terem baixos estoques, insuficiente para manter cultivos sucessivos sem a prática da adubação. $\mathrm{O}$ principal fator que implica na indisponibilidade do K é a grande lixiviação devido à baixa CTC (VILELA et al., 2004). Uma forma de disponibilizar esse nutriente no período em que a planta mais necessita poderia ser por meio de adubação foliar. Para Floss (2006), mesmo que a absorção foliar seja um processo normal para a planta, ela não pode substituir a adubação no solo, pois se baseia em quantidades pequenas de nutrientes, porém pode ser utilizada como artifício para suplementá-la dependendo da cultura, do nutriente e das condições climáticas, sendo influenciada pela quantidade que a planta necessita, absorve e transloca o elemento. Muitos fatores são importantes para o sucesso da adubação foliar devendo-se atentar ao nutriente exigido, dose, estádio correto da cultura, fertilizante utilizado e modo de aplicação e condições locais do tempo.

Diante do exposto o objetivo com este trabalho foi avaliar um programa de adubação na soja em que se variou a dose de fósforo na semeadura, as doses de fertilizantes fluido na semeadura via jato dirigido no sulco e a aplicação de potássio e enxofre foliar.

\section{MATERIAL E MÉTODOS}

O experimento foi conduzido na área da Agropel Sementes, localizada no município de Sinop, no médio-norte do Estado do Mato Grosso. O clima da região conforme a classificação de Köppen-Geiger é do tipo Am, definido como Tropical de Monção. Os valores referentes à precipitação e temperatura durante o periodo do experimento estão descritos na (Figura 1). O solo é de textura argilosa, com $460 \mathrm{~g}$ de argila por kg de solo e tem sua fertilidade em processo de construção, por se tratar de uma área com pouco tempo de cultivo e práticas de adubação e não apresentar níveis adequados de nutrientes no solo. Antes da instalação do experimento, amostras foram retiradas nas profundidades de $0-0,1$ 
e 0,1 - 0,2 m, para reconhecimento da área (Tabela 1). O histórico da área é pastagem degradada, primeiro ano com arroz na safra 2012/2013 com adubação via MAP e permanecendo em pousio até a implantação do experimento.

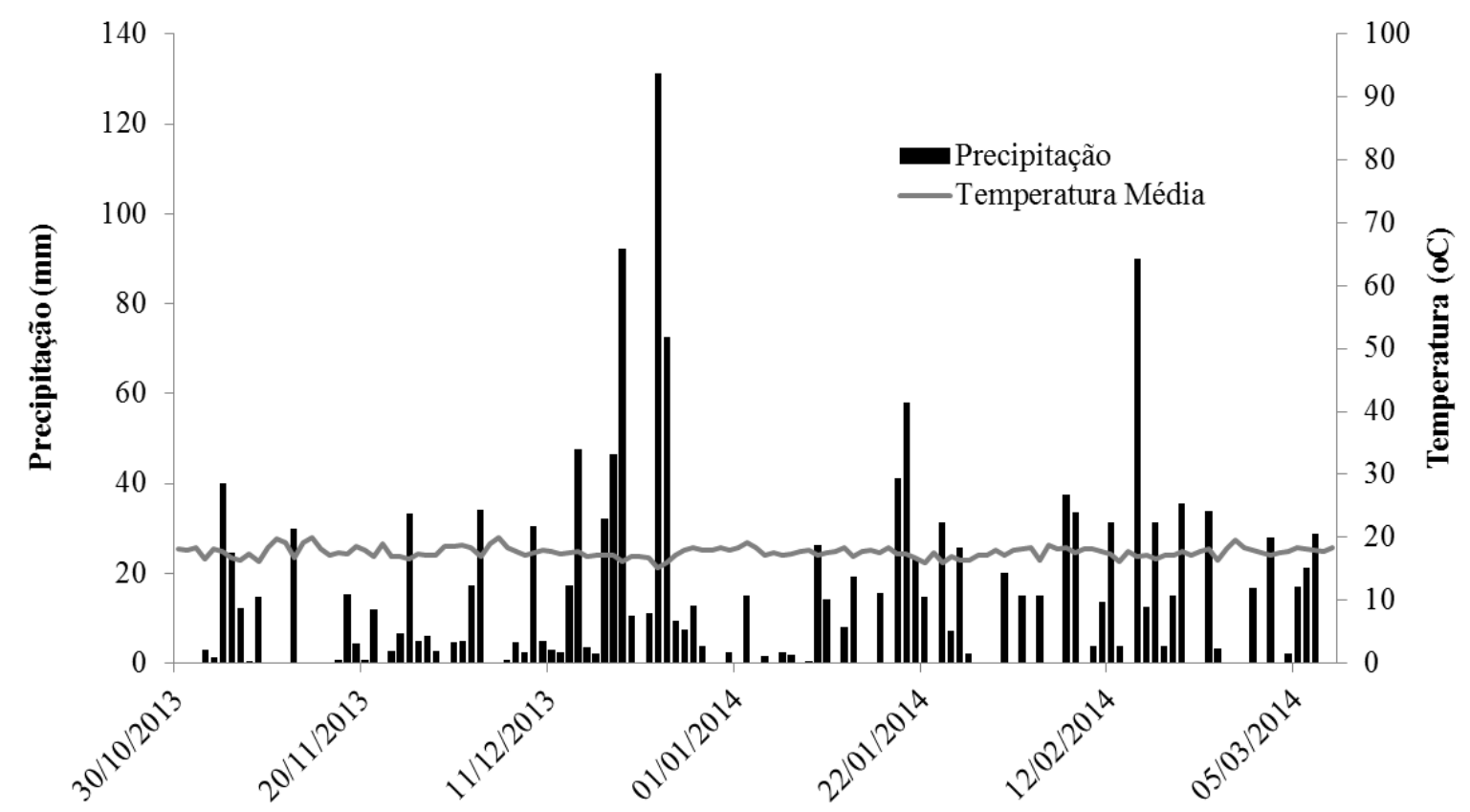

Figura 1. Precipitações e temperaturas do ambiente em todo o ciclo da cultura.

Fonte: Adaptado da estação meteorológica da UFMT Campus Sinop.

Tabela 1. Resultado de análise de solo referente a amostras coletadas em duas profundidades antes da implantação do experimento.

\begin{tabular}{|c|c|c|c|c|c|c|c|c|c|c|c|}
\hline PR & $\mathrm{pH}$ & $\mathrm{P}$ & $\mathrm{K}$ & $\mathrm{Ca}$ & $\mathrm{Mg}$ & Al & $\mathrm{H}$ & $\mathrm{H}+\mathrm{Al}$ & $\mathrm{T}$ & $\mathrm{V} \%$ & $\mathrm{MO}$ \\
\hline $\mathrm{m}$ & $\mathrm{H}_{2} \mathrm{O}$ & \multicolumn{2}{|c|}{$\mathrm{mg} \mathrm{dm}^{-3}$} & - & & $--\mathrm{cn}$ & $1_{c} \mathrm{dm}$ & & - & & $\mathrm{g} \mathrm{dm}^{-3}$ \\
\hline $0-0,1$ & 6,26 & 6,66 & 58,11 & 3,55 & 1,66 & 0,00 & 5,51 & 5,51 & 10,86 & 49,30 & 40,67 \\
\hline $0,1-0,2$ & 5,79 & 4,48 & 33,69 & 2,32 & 1,52 & 0,07 & 6,36 & 6,43 & 10,35 & 37,97 & 24,56 \\
\hline
\end{tabular}

PR: Profundidade de coleta.

Em setembro a área foi dessecada e a semeadura realizada em 30 de outubro de 2013, com a cultivar de soja Monsoy ${ }^{\circledR}$ M - 9144 RR. Os tratamentos consistiram-se de um fatorial $(4 \times 5 \times 2)$ resultante da combinação de 4 doses de $\mathrm{P}_{2} \mathrm{O}_{5}$ aplicadas à lanço na semeadura (fósforo de base), 5 doses de fertilizante líquido a base de $\mathrm{N}$ e $\mathrm{P}$ (fósforo líquido) aplicado com jato dirigido no sulco de semeadura e com ou sem fertilizante foliar líquido (K e $\mathrm{S}$ foliar) aplicados no estádio R3 da soja, perfazendo 40 tratamentos dispostos em um delineamento em blocos casualizados (DBC) com quatro repetições.

$\mathrm{O}$ espaçamento entre linhas foi de $0,50 \mathrm{~m}$ e as parcelas tinham dimensionamento de 2 $\mathrm{m}$ (4 linhas) x $8 \mathrm{~m}$ totalizando $16 \mathrm{~m}^{2}$, sendo que foi considerada área útil os 6 metros centrais e as duas linhas centrais totalizando $6 \mathrm{~m}^{2}$.

As doses de $\mathrm{P}_{2} \mathrm{O}_{5}$ na semeadura foram $\left(0,30,60\right.$ e $\left.90 \mathrm{~kg} \mathrm{ha}^{-1}\right)$, aplicadas à lanço, em área total, sem incorporação, via fertilizante solido granulado da linha "Micro Essentials ${ }^{\circledR}$, contendo $43 \%$ de $\mathrm{P}_{2} \mathrm{O}_{5}, 9 \%$ de N, $8,8 \%$ de $\mathrm{S}, 1,3 \%$ de Ca, $0,1 \%$ de $\mathrm{Cu}, 0,2 \%$ de $\mathrm{Mn}$ e 0,2 $\%$ de Zn. A aplicação superficial, mesmo em áreas novas (segundo ou terceiro ano de 
cultivo) já vem sendo realizada, apesar de não ser a prática mais correta, entretanto, as semeadoras de soja em muitas propriedades já não tem caixa de adubação acoplada, sendo o fertilizante aplicado superficialmente. As doses de P líquido foram $\left(0,5,10,15\right.$ e $\left.20 \mathrm{~L} \mathrm{ha}^{-1}\right)$ via fertilizante com densidade $1,44 \mathrm{~g} \mathrm{~cm}^{-3}, 11 \%$ de $\mathrm{N}$ e $37 \%$ de $\mathrm{P}_{2} \mathrm{O}_{5}$, aplicado no sulco de semeadura, na forma de jato dirigido, com equipamento pressurizado. A dose de $\mathrm{K}$ e $\mathrm{S}$ foliar foi de $2 \mathrm{~L} \mathrm{ha}^{-1}$ via fertilizante foliar líquido com densidade $1,46 \mathrm{~g} \mathrm{~cm}^{-3}, 37 \%$ de $\mathrm{K}_{2} \mathrm{O}$ e $25 \%$ de $\mathrm{S}$ aplicado em R3 (início da frutificação) com equipamento pressurizado.

O manejo de pragas, doenças e invasoras foi típico do cultivo de soja na região. Foram aplicados $150 \mathrm{~kg} \mathrm{ha}^{-1}$ de cloreto de potássio com $60 \%$ de $\mathrm{K}_{2} \mathrm{O}$ em cobertura 25 dias após a semeadura.

Os parâmetros avaliados na planta foram: produtividade com $14 \%$ de umidade calculada a partir da trilha e pesagem dos grãos de todas as plantas da área útil, para cálculo de umidade uma amostra de 100 gramas de cada parcela foi colocada em estufa a $105^{\circ} \mathrm{C}$ por um período de 24 horas, por diferença obteve-se a umidade que foi reajustada para todas as parcelas em $14 \%$, número de grãos por vagem, massa seca de 100 grãos, altura de planta (calculados a partir de seis plantas coletadas na área útil da parcela, sendo que os grãos dessas seis plantas foram incorporados à produtividade).

No solo da área experimental foi avaliado teor de fósforo e potássio com extração por Mehlich1, segundo metodologia proposta por Silva et al. (2009). As amostras de solo foram coletadas no sulco da semeadura, na profundidade de 0 a $0,1 \mathrm{~m}$, quando a soja se encontrava no estádio fenológico V7, com trado calador, sendo colhidos em cada parcela dois pontos (furos sobre a linha de semeadura). Como a aplicação de K e S foliar ainda não havia sido realizada, cada bloco continha uma parcela repetida para cada tratamento, essas foram unidas para formar uma única amostra totalizando apenas 20 tratamentos e um fatorial 4 X 5 para os parâmetros de solo.

Os dados obtidos nas diferentes avaliações foram submetidos ao teste $\mathrm{F}$, para análise de variância e, os efeitos dos tratamentos, quando significativos a $5 \%$ de probabilidade, foram submetidos ao teste $\mathrm{T}$ (LSD) para $\mathrm{K}$ e $\mathrm{S}$ foliar e regressão para os demais.

\section{RESULTADOS E DISCUSSÃO}

As variáveis massa de 100 grãos e número de grãos por vagem não apresentaram diferença significativa em relação às doses de fósforo de base (Tabela 2). Araújo et al. (2005) avaliaram doses de fósforo em quatro cultivares e também não obtiveram diferença significativa para massa de 100 grãos. Gonçalves Júnior et al. (2010) testaram doses de fósforo e potássio sendo essas 0 de $\mathrm{K}$ e $\mathrm{P}$, recomendada 80 de $\mathrm{P}$ e 60 de $\mathrm{K}$ e dobro da recomendada 160 de $\mathrm{P}$ e 120 de $\mathrm{K}$, sendo que para as variáveis número de grãos por vagem e massa de 100 grãos não houve diferença significativa, mostrando que essas duas variáveis são pouco influenciadas pela adubação fosfatada até mesmo em doses altas.

Rosolem e Tavares (2006) cultivaram plantas de soja em vasos e induziram uma deficiência de fósforo na ocasião do aparecimento das primeiras gemas florais constatando 
que o número de grãos por vagem não foi influenciado pela ausência ou não de fósforo, corroborando com o presente trabalho em que não foi observada influência do fósforo sobre o número de grãos por vagem.

Tabela 2. Análise de variância (valores de F) para altura de plantas (ALT), massa de 100 grãos (M100), número de grãos por vagem (NGV) e produtividade da soja (PRO), em função dos diferentes tratamentos e médias dos tratamentos com e sem K e S Foliar, safra 2013/2014 Sinop, MT.

\begin{tabular}{lcccc}
\hline Causa de Variação & ALT $(\mathrm{cm})$ & M100 $(\mathrm{g})$ & NGV & PRO $\left(\mathrm{kg} \mathrm{ha}^{-1}\right)$ \\
\hline Doses K e S Foliar & & & & \\
Sem & $85,61 \mathrm{a}$ & $14,10 \mathrm{a}$ & $2,07 \mathrm{a}$ & $3572 \mathrm{a}$ \\
Com & $82,39 \mathrm{~b}$ & $14,03 \mathrm{a}$ & $2,09 \mathrm{a}$ & $3764 \mathrm{a}$ \\
\hline DMS (5 \%) & 2,57 & 0,35 & 0,027 & 201,44 \\
\hline K e S Foliar (a) & $6,17^{*}$ & $0,13^{\mathrm{ns}}$ & $1,59^{\mathrm{ns}}$ & $3,57^{\mathrm{ns}}$ \\
Fósforo de Base (b) & $10,22^{*}$ & $0,63^{\mathrm{ns}}$ & $1,33^{\mathrm{ns}}$ & $3,05^{*}$ \\
Fósforo Liquido (c) & $1,48^{\mathrm{ns}}$ & $0,79^{\mathrm{ns}}$ & $1,25^{\mathrm{ns}}$ & $0,57^{\mathrm{ns}}$ \\
a x b & $0,73^{\mathrm{ns}}$ & $0,60^{\mathrm{ns}}$ & $2,94^{*}$ & $1,09^{\mathrm{ns}}$ \\
a x c & $0,34^{\mathrm{ns}}$ & $1,73^{\mathrm{ns}}$ & $0,79^{\mathrm{ns}}$ & $0,53^{\mathrm{ns}}$ \\
b x c & $0,82^{\mathrm{ns}}$ & $0,90^{\mathrm{ns}}$ & $1,63^{\mathrm{ns}}$ & $0,68^{\mathrm{ns}}$ \\
a x b x c & $1,03^{\mathrm{ns}}$ & $0,74^{\mathrm{ns}}$ & $1,06^{\mathrm{ns}}$ & $1,42^{\mathrm{ns}}$ \\
\hline Média & 84,00 & 14,06 & 2,08 & 3668,73 \\
\hline CV \% & 9,75 & 8,00 & 4,07 & 17,53 \\
\hline
\end{tabular}

${ }^{n s}$ Valores não diferem segundo teste $\mathrm{F} \mathrm{e}$ * significativo a $5 \%$ de significância segundo e teste $\mathrm{F}$.

A altura de plantas e a produtividade da soja apresentaram diferença significativa em relação às doses de fósforo de base, ambas apresentando um efeito linear crescente (Figura 2). Este comportamento é típico em solos de Cerrado, em que a disponibilidade de $\mathrm{P}$ é inicialmente baixa (antes do experimento 6,66 e 4,48 $\mathrm{mg} \mathrm{dm}^{-3}$ nas profundidades de $0-0,1$ e 0,1 - 0,2 m respectivamente). Devido a essencialidade do fósforo é notório que seu fornecimento em solos pobres resulte em incrementos produtivos. Alcântara Neto et al. (2010) também observaram diferença significativa na produtividade da soja testando doses de 0 a $140 \mathrm{~kg} \mathrm{ha}^{-1}$ de $\mathrm{P}_{2} \mathrm{O}_{5}$ em solo com $23 \%$ de argila, sendo que o efeito foi quadrático. $\mathrm{O}$ efeito linear na produtividade em relação à aplicação de $\mathrm{P}$ deve-se as baixas doses utilizadas e à aplicação superficial, que favoreceu o menor contato raiz-nutriente. Broch et al. (2008) utilizando doses elevadas $\left(0,100,200\right.$ e $300 \mathrm{~kg} \mathrm{ha}^{-1}$ de $\left.\mathrm{P}_{2} \mathrm{O}_{5}\right)$ em solo muito argiloso por meio de superfosfato triplo tem resultados que corroboram com os deste trabalho observando produtividades crescentes com e sem a utilização de calcário e gesso. 


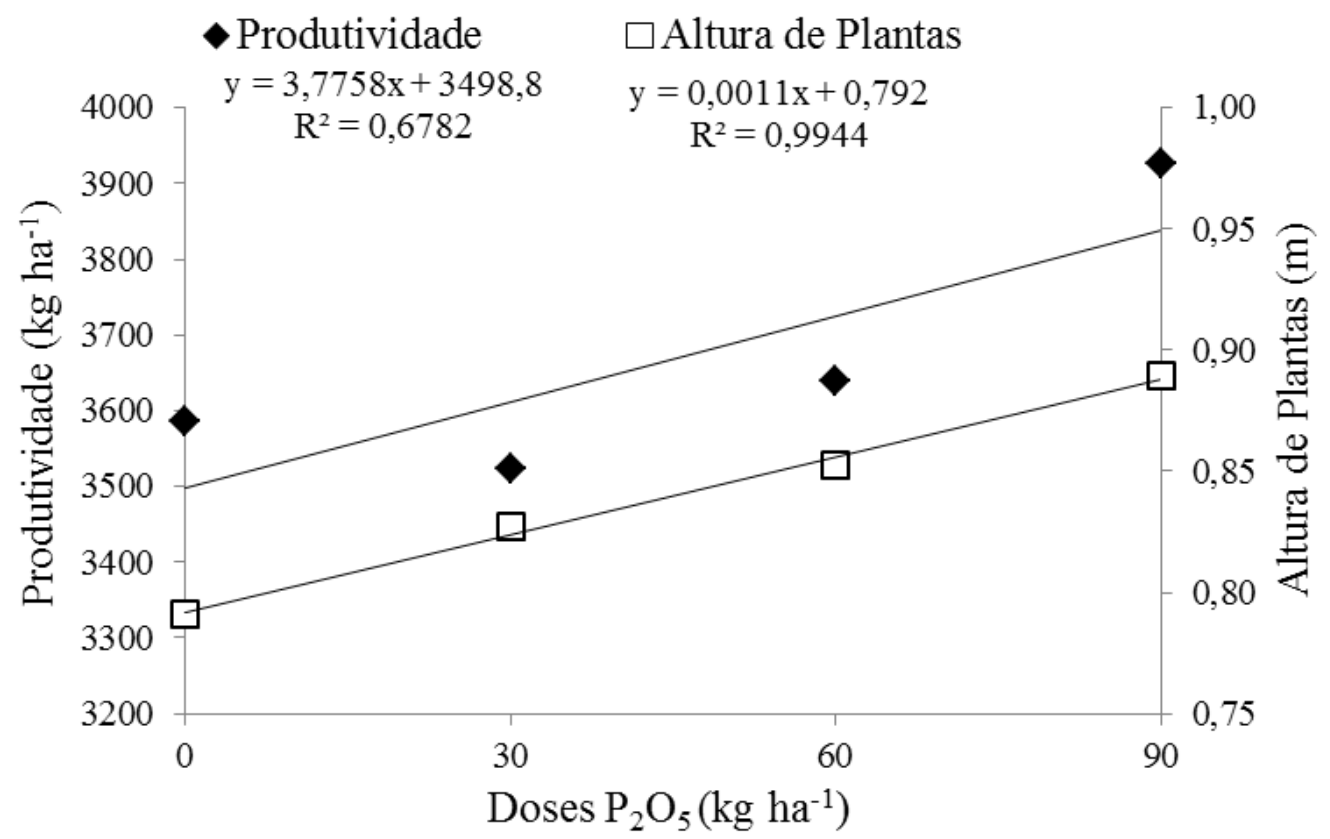

Figura 2. Produtividade $\mathrm{kg} \mathrm{ha}^{-1}$ e altura de plantas da soja em relação as doses de fósforo de base, safra 2013/2014 Sinop, MT.

A argila pode apresentar um efeito de tamponamento de fósforo no solo, pode-se observar a influência da argila no trabalho de Bedin et al. (2003) que testaram fosfatos na produção da soja em vasos com 3 solos de diferentes capacidades tampão de fosfato sendo

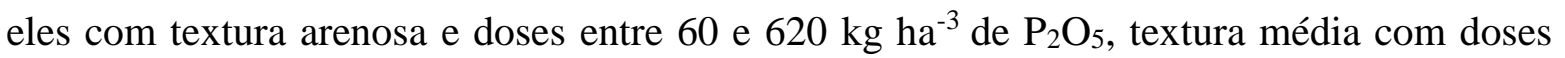
entre 70 e $700 \mathrm{~kg} \mathrm{ha}^{-3}$ de $\mathrm{P}_{2} \mathrm{O}_{5}$ e textura argilosa com doses entre 80 e $800 \mathrm{~kg} \mathrm{ha}^{-3} \mathrm{de} \mathrm{P}_{2} \mathrm{O}_{5}$, as doses foram definidas com base no fósforo remanescente, sendo que em solos arenosos a produção de grãos tendeu a ser maior que nos demais, porém o argiloso foi o único que teve aumento de produção de grãos continuo com as doses de $\mathrm{P}$.

Valadão Junior et al. (2008) testaram doses de fósforo em duas cultivares de soja variando de (0 a $177 \mathrm{~kg} \mathrm{ha}^{-1}$ de $\left.\mathrm{P}_{2} \mathrm{O}_{5}\right)$ em solo com $40 \%$ de argila e Araújo et al. (2005) testaram doses de fósforo em quatro cultivares variando de $\left(0\right.$ a $270 \mathrm{~kg} \mathrm{ha}^{-1}$ de $\left.\mathrm{P}_{2} \mathrm{O}_{5}\right)$ em solo com $26 \%$ de argila, ambos observaram efeito quadrático, sendo que as maiores alturas de plantas foram encontradas nas doses de 140 e $192 \mathrm{~kg} \mathrm{ha}^{-1}$ de $\mathrm{P}_{2} \mathrm{O}_{5}$ respectivamente, o presente trabalho apresentou efeito linear provavelmente pela maior dose ser de apenas 90 $\mathrm{kg} \mathrm{ha}^{-1}$.

Em relação a aplicação de $\mathrm{P}$ e $\mathrm{N}$ com jato liquido no sulco não houve diferença significativa para nenhum dos parâmetros (altura de planta, peso de 100 grãos, número de grãos por vagem e produtividade). Rezende et al. (2005) testaram a adubação foliar com P na cultura da soja em diferentes estádios, verificaram um ganho em produtividade quando aplicado apenas no estádio V5, ou quando aplicado em diferentes estádios. Como a adubação foliar é baseada em pequenas quantidades de nutrientes sua aplicação fracionada é importante, principalmente quando se trata de macronutrientes, condição que não ocorreu nesse estudo sendo que só realizou-se uma aplicação no sulco de semeadura.

Cultura Agronômica, Ilha Solteira, v.25, n.1, p.93-104, 2016 
Com a aplicação de $\mathrm{K}$ e $\mathrm{S}$ foliar, não houve diferença significativa para número de grãos por vagem, massa de 100 grãos e produtividade, porém a altura de plantas diferiu significativamente, sendo menor com a aplicação dos nutrientes. Fabris et al. (2013) aplicando doses de fertilizante mineral misto foliar contendo vários nutrientes dentre eles o K e o S, em três estádios de desenvolvimento da soja V8, R2 e R5 também não observaram diferença significativa em relação a produtividade porém a altura de planta foi significativa com a maior altura na maior dose diferenciando-se dos dados obtidos em $\mathrm{K}$ e $\mathrm{S}$ foliar que foi obtida a maior altura de plantas na ausência do fertilizante. Passos et al. (2008) realizaram estudos com diferentes doses de nitrato de potássio via foliar aplicadas no estádio R3 e não obtiveram diferença significativa para altura de planta, massa de grãos, número de grãos por vagem e produtividade.

Testando S elementar aplicado na folha e no solo, Vitti et al. (2007) observaram que independente do método de aplicação o enxofre resultou em aumento de produtividade e as plantas que receberam $S$ foliar não diferiram das que receberam enxofre via solo. Rezende et al. (2009) testaram doses de dois produtos; o primeiro com $26 \%$ de $\mathrm{S}$, densidade 1,16 nas dosagens 1,2 e $3 \mathrm{~L} \mathrm{ha}^{-1}$ e o segundo com $56 \%$ de $\mathrm{S}$, densidade 1,43 com doses $0,5,1$ e 1,5 $\mathrm{L} \mathrm{ha}^{-1}$ e um tratamento controle aplicados via foliar na cultura da soja no estádio R3. Os resultados mostram que as duas maiores doses nos dois produtos foram significativamente maiores que as menores doses e o controle mostrando a eficiência da adubação foliar.

Tabela 3. Interação entre fósforo de base e K e S foliar para a variável, número de grãos por vagem, safra 2013/2014 Sinop, MT.

\begin{tabular}{ccccc}
\hline K e S Foliar & \multicolumn{4}{c}{ Fósforo de base $\left(\mathrm{kg} \mathrm{ha}^{-1} \mathrm{de}_{2} \mathrm{O}_{5}\right)$} \\
\cline { 2 - 5 } & 0 & 30 & 60 & 90 \\
\hline Sem & $2,12 \mathrm{a}$ & $2,04 \mathrm{a}$ & $2,08 \mathrm{a}$ & $2,05 \mathrm{~b}$ \\
Com & $2,08 \mathrm{a}$ & $2,08 \mathrm{a}$ & $2,08 \mathrm{a}$ & $2,12 \mathrm{a}$ \\
\hline
\end{tabular}

Médias seguidas pela mesma letra na coluna não diferem estatisticamente pelo teste T $5 \%$ de probabilidade.

Houve interação significativa entre $\mathrm{K}$ e $\mathrm{S}$ foliar e a dose de fósforo de base $90 \mathrm{~kg} \mathrm{ha}^{-1}$ de $\mathrm{P}_{2} \mathrm{O}_{5}$, sendo que o tratamento que recebeu o produto foliar foi superior ao que não recebeu. Guareschi et al. (2008) avaliando várias formas de adubação fosfatada e potássica na cultura da soja não observaram diferença significativa entre as parcelas que receberam adubação e a testemunha em relação ao número de grãos por vagem.

Tabela 4. Análise de variância (valores de F) para fósforo e potássio de solo coletadas na profundidade de $0-0,1 \mathrm{~m}$ no estádio V7 da cultura da soja, em função dos diferentes tratamentos, safra 2013/2014 Sinop, MT.

\begin{tabular}{lcc}
\hline Causa de Variação & $\mathrm{P}\left(\mathrm{mg} \mathrm{dm}^{-3}\right)$ & $\mathrm{K}\left(\mathrm{mg} \mathrm{dm}^{-3}\right)$ \\
\hline Fósforo de Base (a) & $6,81^{*}$ & $10,61^{*}$ \\
Fósforo Líquido (b) & $1,42^{\mathrm{ns}}$ & $0,98^{\mathrm{ns}}$ \\
$\mathrm{a} \mathrm{x} \mathrm{b}$ & $0,38^{\mathrm{ns}}$ & $1,12^{\mathrm{ns}}$ \\
\hline Média & 10,03 & 58,20 \\
\hline CV \% & 36,99 & 18,20 \\
\hline
\end{tabular}

ns Valores não diferem segundo teste $\mathrm{F}$; * significativo a 5 \% de significância segundo o teste $\mathrm{F}$.

Cultura Agronômica, Ilha Solteira, v.25, n.1, p.93-104, 2016 
Nenhum dos parâmetros avaliados no solo apresentou diferença significativa em relação as doses de fósforo líquido, e não houve interação entre $\mathrm{P}$ liquido e $\mathrm{P}$ de base, enquanto $\mathrm{P}$ e $\mathrm{K}$ no solo diferiram significativamente com as doses de fósforo de base (Tabela 4), apresentando efeito linear crescente para P e decrescente para K (Figura 3).

A redução dos valores de $\mathrm{K}$ no solo com o aumento das doses de $\mathrm{P}$ aplicado no sulco, possivelmente ocorreu devido a absorção de K pela cultura da soja, pois para cada tonelada de grãos produzidos, aproximadamente $38 \mathrm{~kg}$ de $\mathrm{K}_{2} \mathrm{O}$ são necessários (EMBRAPA, 2011), e, como a produtividade da cultura respondeu positivamente a adubação fosfatada de base, houve necessidade de maior extração de $\mathrm{K}$ nos tratamentos que produziram mais, ocorrendo dessa forma uma redução dos níveis de $\mathrm{K}$ no solo proporcional ao aumento de produtividade.

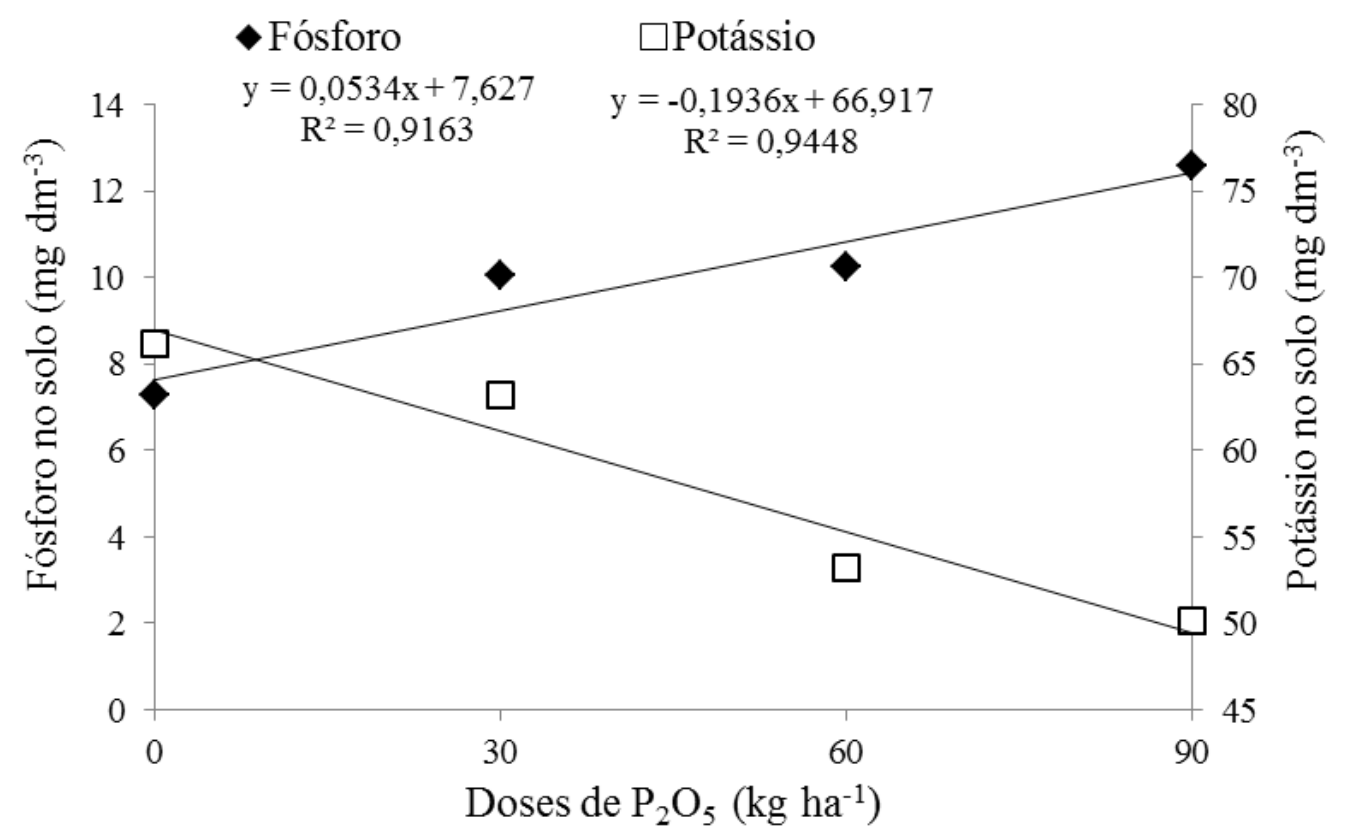

Figura 3. Teores de fósforo e potássio no solo em relação as doses de fósforo de base, safra 2013/2014 Sinop, MT.

A soja absorve 15,4 kg de $\mathrm{P}_{2} \mathrm{O}_{5}$ por tonelada de grão produzido (EMBRAPA, 2011), neste sentido a não diferença estatística de $\mathrm{P}$ no solo em relação às doses de fósforo líquido pode estar relacionada ao fato de esta ser uma fonte de $\mathrm{P}$ prontamente disponível, que provavelmente foi extraída pela planta nos estádios iniciais, resultando assim em um incremento na produtividade e por consequência aproveitamento do $\mathrm{P}$ proveniente do fósforo líquido nas maiores doses, o que justifica os valores de P no solo para a aplicação de fósforo líquido iguais, independentes da dose.

A adubação com fósforo tende a aumentar os seus níveis no solo sendo que seu aumento está relacionado com a maior produtividade, pois mesmo que o P não seja um dos nutrientes mais exigidos pela soja, ele é o que mais limita a sua produção no Brasil, devido aos baixos teores, alta fixação e baixos valores de recuperação pelas plantas do P aplicado (OLIVEIRA JÚNIOR et al., 2010), principalmente em solos de cultivo recente, sem estoque de $\mathrm{P}$ na camada superficial (dados iniciais mostram $\mathrm{P}=6 \mathrm{mg} \mathrm{dm}^{-3}$ ). Por esses motivos o $\mathrm{P}$, 
aplicado via fertilizante líquido pode ser uma alternativa para disponibilizar parte do nutriente exigido pela planta, sendo que ele é prontamente disponibilizado, evitando dessa forma a grande fixação no solo.

Gonçalves Júnior et al. (2010) em solo com $24 \%$ de argila com teor inicial de P de 14 $\mathrm{mg} \mathrm{dm}{ }^{-3}$ e de $\mathrm{K} 0,16 \mathrm{cmol}_{\mathrm{c}} \mathrm{dm}^{-3}$ na camada de 0 a $5 \mathrm{~cm}$ e teor inicial de $\mathrm{P}$ de $12,23 \mathrm{mg} \mathrm{dm}^{-3}$ e de $\mathrm{K} 0,12 \mathrm{cmol}_{\mathrm{c}} \mathrm{dm}^{-3}$ na camada de 0 a $20 \mathrm{~cm}$, executando experimento na cultura da soja coletaram amostras de solo no florescimento e constataram que onde não se adubou com $\mathrm{K}$ e $\mathrm{P}$ o teor de $\mathrm{P}$ foi menor que o inicial, e onde se adubou com a dose recomendada e o dobro da recomendada de $\mathrm{P}$ e $\mathrm{K}$ o teor no solo foi crescente, corroborando com os teores de fósforo do presente trabalho que também responderam de forma crescente a adubação.

\section{CONCLUSÃO}

A aplicação de fósforo de base aumentou a concentração do nutriente no solo repercutindo assim em maior produtividade, acarretando maior extração de potássio do solo.

A produtividade de grãos não aumentou significativamente com a aplicação de fósforo via fertilizante liquido no sulco de semeadura e nem com o fornecimento de $\mathrm{K}$ e $\mathrm{S}$ foliar.

\section{REFERÊNCIAS BIBLIOGRÁFICAS}

AlCÂNTARA NETO, F.; GRAVINA, G. A.; SOUZA, N. O. S.; BEZERRA, A. A. C. Adubação fosfatada na cultura da soja na microrregião do Alto Médio Gurguéia. Revista Ciência Agronômica, Fortaleza, v. 41, n. 2, p.266-271, 2010.

ARAÚJO, W. F.; SAMPAIO, R. A.; MEDEIROS, R. D. Resposta de cultivares de soja à adubação fosfatada. Revista Ciência Agronômica, Fortaleza, v. 36, n. 2, p.129-134, 2005.

BEDIN, I.; FURTINI NETO, A. E.; RESENDE, A. V.; FAQUIN, V.; TOKURA, A. M.; SANTOS, J. Z. L. Fertilizantes fosfatados e produção da soja em solos com diferentes capacidades tampão de fosfato. Revista Brasileira de Ciência do Solo, Viçosa, v. 27, n. 4, p.639-646, 2003.

BORKERT, C. M.; YORINORI, J. T.; CORRÊA-FERREIRA, B. S.; ALMEIDA, A. M. R.; FERREIRA, L. P.; SFREDO, G. J. Seja o doutor da sua soja. Potafós - Informações Agronômicas, Piracicaba, n. 66, p.1-17, 1994. Disponível em: http://www.ipni.net/. Acesso em: 19 jul. 2016. (Aquivo do Agrônomo, n. 5).

BROCH, D. L.; NOLLA, A.; DEL QUIQUI, E. M.; POSSENTI, J. C. Influência no rendimento de plantas de soja pela aplicação de fósforo, calcário e gesso em um Latossolo sob plantio direto. Revista Ciências Exatas e Naturais, Guarapuava, v. 10, n. 2, p.211-220, 2008.

CANTARELlA, H.; MONTEZANO, Z. F. Nitrogênio e Enxofre. In. PROCHNOW, L. I.; CASARIN, V.; STIPP, S. R. Boas praticas para o uso eficiente de fertilizantes: nutrientes. v. 2. Piracicaba: IPNI - Brasil, 2010. Cap. 1, p. 5-70.

Cultura Agronômica, Ilha Solteira, v.25, n.1, p.93-104, 2016 
EMBRAPA SOJA. Tecnologias de produção de soja - Região Central do Brasil 2012 e 2013. Londrina: Embrapa Soja. 2011, n. 15. p. 261. Disponível em: http://www.cnpso.embrapa.br/. Acesso em: 19 jul. 2016.

FABRIS, D. N.; SELAJA, O. L.; FINAMORE, W. L. M. Avaliação biométrica da soja com diferentes doses de fertilizante mineral misto em aplicação foliar. Revista de Ciências Exatas e da Terra UNIGRAN, Dourados, v. 2, n. 1, p.50-60, 2013.

FLOSS, E. L. Fisiologia das plantas cultivadas: o estudo do que está por trás do que se vê. 3. ed. Passo Fundo: Universidade de Passo Fundo, 2006. 751 p.

GONÇALVES JÚNIOR, A. C.; NACKE, H.; MARENGONI, N. G.; CARVALHO, E. A.; COELHO, G. F. Produtividade e componentes de produção da soja adubada com diferentes doses de fósforo, potássio e zinco. Ciência e Agrotecnologia, Lavras, v. 34, n. 3, p.660$666,2010$.

GRANT, C. A.; FlATEN, D. N.; TOMASCIENWICZ, D. J. SHEPPARD, S. C. A importância do fósforo no desenvolvimento inicial da planta. Potafós - Informações Agronômicas, Piracicaba, n. 95, p.1-16, 2001. Disponível em: http://www.ipni.net/. Acesso em: 19 jul. 2016.

GUARESCHI, R. F.; GAZOLLA, P. R.; SOUCHIE, E. L.; ROCHA, A. C. Adubação fosfatada e potássica na semeadura e a lanço antecipada na cultura da soja cultivada em solo de Cerrado. Ciências Agrárias, Londrina, v. 29, n. 4, p.769-774, 2008.

MALAVOLTA, E. Manual de nutrição mineral de plantas. São Paulo: Agronômica Ceres, 2006. 638 p.

MASCARENHAS, H. A. A.; TANAKA, R. T.; WUTKE, E. B.; BRAGA, N. R.; MIRANDA, M. A. C. Potássio para a soja. Potafos - Informações Agronômicas, Piracicaba, n. 105, p.1-2, 2004. Disponível em: http://www.ipni.net/. Acesso em: 19 jul. 2016.

MEURER, E. J. Potássio. In. FERNANDES, M. S. Nutrição Mineral de Plantas. Viçosa: Sociedade Brasileira de Ciência do Solo, 2006. Cap. 11, p. 281-298.

OLIVEIRA JÚNIOR, A.; CASTRO, C.; KLEPKER, D.; OLIVEIRA, F. A. Soja. In. PROCHNOW, L. I.; CASARIN, V.; STIPP, S. R. Boas praticas para o uso eficiente de fertilizantes: culturas; v. 3 Piracicaba: IPNI - Brasil, 2010. Cap. 1, p. 5-42. (Anais)

PASSOS, A. M. A.; REZENDE, P. M.; CARVALHO, A. A.; SAVELLI, R. A. M. Cinetina e nitrato de potássio em características agronômicas de soja. Pesquisa Agropecuária Brasileira, Brasília, v. 43, n. 7, p.925-928, 2008.

REZENDE, P, M.; GRIS, C. F.; CARVALHO, J. G.; GOMES, L. L.; BOTTINO, L. Adubação Foliar. I. Épocas de Aplicação de Fósforo na Cultura da Soja. Ciência e Agrotecnologia, Lavras, v. 29, n. 6, p.1105-1111, 2005.

Cultura Agronômica, Ilha Solteira, v.25, n.1, p.93-104, 2016 
REZENDE, P. M.; CARVALHO, E. R.; SANTOS, J. P.; DEANDRADE, M. J. B.; ALCANTARA, H. P. Enxofre aplicado via foliar na cultura da soja [Glycine max (L.) Merrill]. Ciência e Agrotecnologia, Lavras, v. 33, n. 5, p.1255-1259, 2009.

ROSOLEM, C. A.; TAVARES, C. M. Sintomas de deficiência tardia de fósforo em soja. Revista Brasileira de Ciência do Solo, Viçosa, v. 30, n. 2, p.385-389, 2006.

SILVA, C. S.; ABREU, M. F.; PÉREZ, D. V.; EIRA, P. A.; ABREU, C. A.; RAIJ, B. V.; GIANEllo, C.; COElHO, A. M.; QUAGGIO, J. A.; TEDESCO, M. J.; SIlVA, C. A.; BARRETO, W. O. Método de análises químicas para avaliação da fertilidade do solo. In. SILVA, F. C. Manual de análises químicas de solos, plantas e fertilizantes. 2 ed. Brasília: Embrapa Informação Tecnológica, 2009. Parte 2. Cap. 1, p. 107-191.

SILVA, D. J.; VENEGAS, V. H. A.; RUIZ, H. A. Transporte de enxofre para as raízes de soja em três solos de Minas Gerais. Pesquisa Agropecuária Brasileira, Brasília, v. 37, n. 8, p.1161-1167, 2002.

TAIZ, L.; ZEIGER, E. Fisiologia Vegetal. 5. ed. Porto Alegre: Artmed, 2013. 918 p.

VALADÃO JÚNIOR, D. D.; BERGAMIN, A. C.; VENTUROSO, L. R.; SCHLINDWEIN, J. A.; CARON, B. O.; SCHMIDT, D. Adubação fosfatada na cultura da soja em Rondônia. Scientia Agraria, Curitiba, v. 9, n. 3, p.369-375, 2008.

VILELA, L.; SOUSA, D. M. G.; SILVA, J. E. Adubação potássica. In. SOUSA, D. M. G.; LOBATO, E. Cerrado Correção do Solo e Adubação. 2. ed. Brasília: Embrapa Informação Tecnológica, 2004. Cap. 7, p. 169-182.

VITTI, G. C.; FAVARIN, J. L.; LUIZ ANTONIO GALLO, L. A.; PIEDADE, S. M. S.; FARIA, M. R. M.; E CICARONE, F. Assimilação foliar de enxofre elementar pela soja. Pesquisa Agropecuária Brasileira, Brasília, v. 42, n. 2, p.225-229, 2007. 